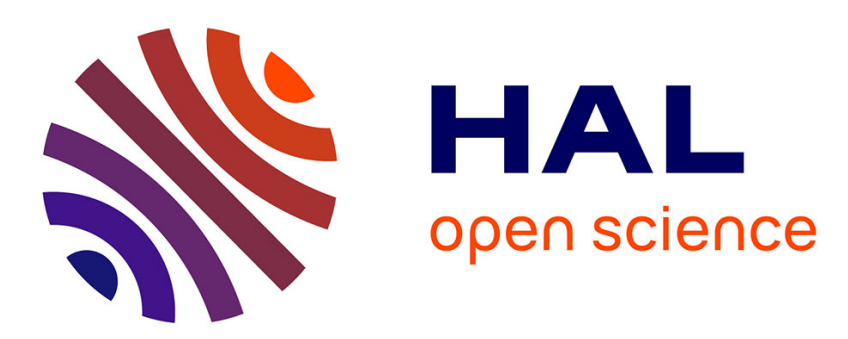

\title{
Encrucijada de guerra en mujeres peruanas: Augusta La Torre y el Movimiento Femenino Popular
}

\author{
Anouk Guiné
}

\section{To cite this version:}

Anouk Guiné. Encrucijada de guerra en mujeres peruanas: Augusta La Torre y el Movimiento Femenino Popular. Millars. Espai i història , 2016, Crisis y rupturas en América Latina, 1970-1980, XLI (2), 10.6035/Millars.2016.41.5 . hal-02320575

\section{HAL Id: hal-02320575 https://hal.science/hal-02320575}

Submitted on 18 Oct 2019

HAL is a multi-disciplinary open access archive for the deposit and dissemination of scientific research documents, whether they are published or not. The documents may come from teaching and research institutions in France or abroad, or from public or private research centers.
L'archive ouverte pluridisciplinaire HAL, est destinée au dépôt et à la diffusion de documents scientifiques de niveau recherche, publiés ou non, émanant des établissements d'enseignement et de recherche français ou étrangers, des laboratoires publics ou privés. 
X니 2016/2

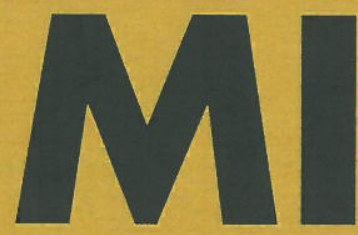

ESPAI I HISTÒRIA

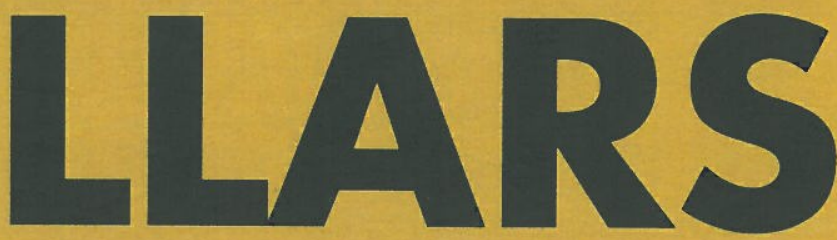

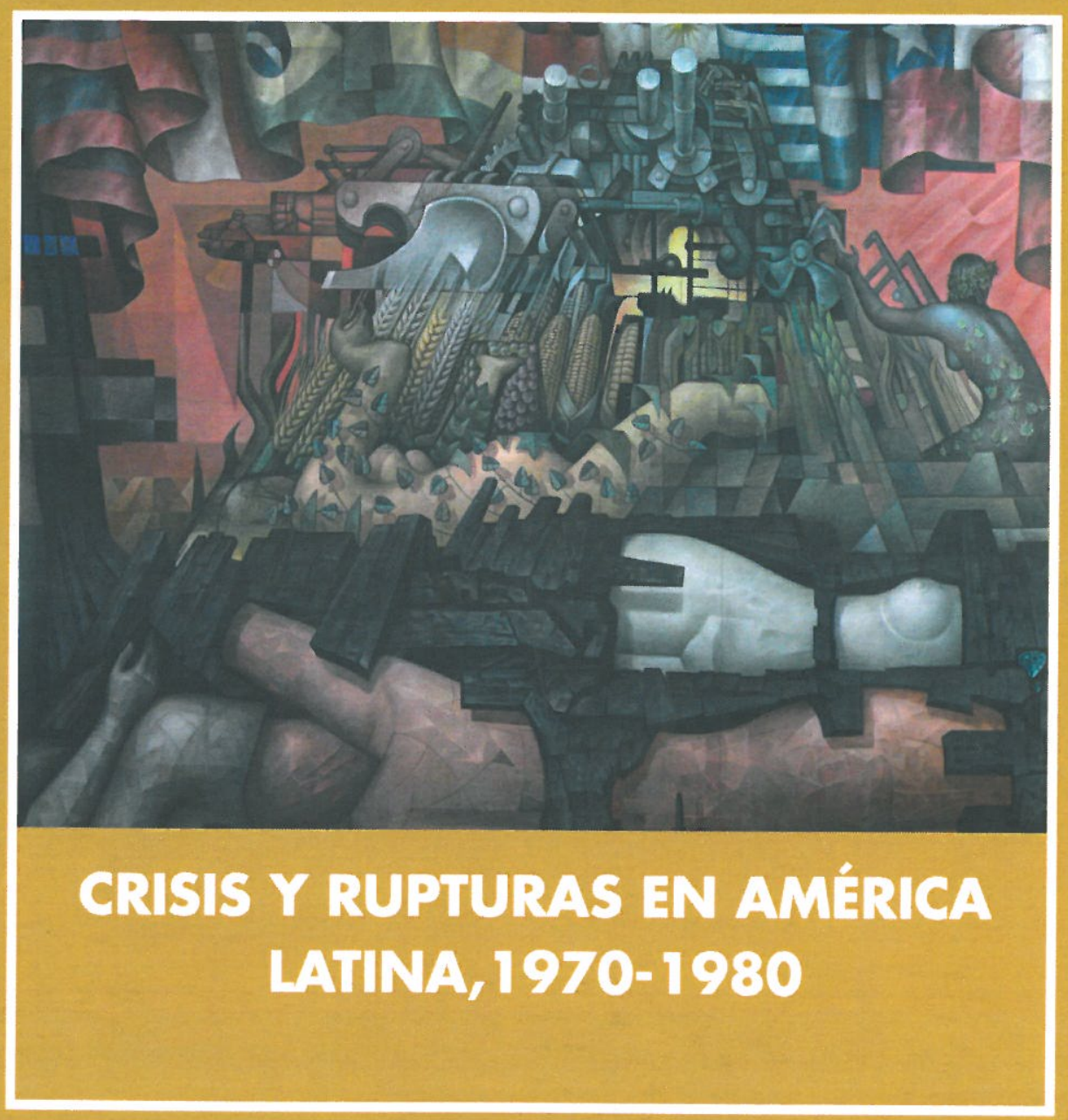

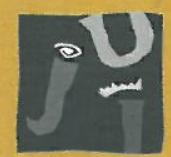

UNIVERSITAT

JAUME・I 


\title{
ENCRUCIJADA DE GUERRA EN MUJERES \\ PERUANAS: AUGUSTA LA TORRE Y EL \\ MOVIMIENTO FEMENINO POPULAR
}

\section{PERUVIAN WOMEN AT THE CROSSROADS OF WAR: AUGUSTA LA TORRE AND THE WOMEN'S POPULAR MOVEMENT}

\author{
Anouk Guiné \\ Université du Havre \\ Groupe de Recherches Identités et Cultures (GRIC)
}

\section{RESUMEN}

Desde los años 1960, Augusta La Torre, segunda dirigente del Partido Comunista del Perú-Sendero Luminoso (PCP-SL) formado en 1970, funda el Movimiento Femenino Popular (MFP). Éste marca el inicio de un tipo de "feminismo proletario" inspirado en Marx, Engels, Mao y Mariátegui. Es radicalmente diferente y opuesto a otros movimientos populares de mujeres de la época. Veremos cuales han sido los antecedentes y el papel del MFP en el contexto de los movimientos sociales de campesinos y obreros iniciados en los años 1960, y de la "lucha armada" que se libró contra el Estado peruano entre 1980 y 1992 . El presente trabajo opera una ruptura epistomológica para acercarse a un entendimiento contra-hegemónico de la historia de las mujeres del PCP-SL.

Palabras clave: Perú, movimientos sociales, movimientos de mujeres, Sendero Luminoso, conflicto armado.

\section{ABSTRACT}

Augusta La Torre (second-in-command of the Communist Party of Peru-Shining Path (PCPSP) formed in 1970) founded the Women's Popular Movement (WPM) in the 1960s. This marked the beginning of a type of "proletarian feminism" which took its inspiration from Marx, Engels, Mao and Mariátegui. It is radically different from and opposed to other Peruvian popular women's movements of that time. This paper traces the history and the role of the WPM in the context of the national peasants' and workers' social movements of the 1960s, and the "armed struggle" waged against the Peruvian State from 1980 to 1992. The article makes an epistemological break in order to attempt to come to a counter-hegemonic understanding of the history of the women of Shining Path.

Keywords: Peru, Social Movements, Women's Movements, Shining Path, Armed Conflict. 
La guerra civil que declaró una parte de la población peruana a su propio Estado en 1980, tiene sus orígenes en una historia postcolonial caracterizada por profundas desigualdades sociales, económicas y culturales. El clima socio-político internacional de los años 1960 -provocado por la guerra fría entre el modelo de gobierno capitalista liderado por los Estados Unidos (EE.UU.) y el modelo comunista encabezado por la ex Union Soviética, así como marcado por la represión del comunismo a nivel mundial por los EU- es la tela de fondo de los movimientos de protesta iniciados por la ciudadanía en cada continente, y como parte de ello los movimientos revolucionarios latinoamericanos politicamente organizados contra las dictaduras militares implementadas y financiadas en América Latina por los EE.UU. En el Perú, las luchas de las clases más pobres se dieron en contra del llamado "Gobierno Revolucionario de las Fuerzas Armadas» del General Juan Velasco Alvarado de 1968 a 1975 como parte de la Alianza para el Progreso lanzada en 1961 por los EE.UU., así como en oposición a la dictadura militar del General Francisco Morales Bermudez de 1975 a 1980, haciendo del Perú un miembro esporádico de la Operación Condor.

La «Guerra Popular» llevada a cabo en el Perú desde Ayacucho (sierra centro sur) entre 1980 y 1992, se inscribe en esta lógica. Según la Comisión Permanente de Historia del Ejército (CPHE), «lo más patente de la situación económica (en Perú)... era la gran diferencia que marcaba a ricos y pobres...la coexistencia era simplemente un abismo que comenzaba en el boato de pocos y la supervivencia extrema de muchos» (COMISIÓN PERMANENTE DE HISTORIA DEL EJÉRCITO DEL PERÚ, 2012, p. 19). El $80 \%$ de la población pobre vivía en los Andes (lbid.), del cual un $40 \%$ era compuesto por el campesinado rural indígena que vivía en la extrema pobreza (SCOTT PALMER, 2014, p. 132). El 20\% restante vivía en asentamientos humanos (infravivienda): «Espacios eriazos que se caracterizaban por la ausencia de cualquier comodidad para sus habitantes: sin luz, agua, desaguë y viviendas de estera, sin piso» (COMISIÓN PERMANENTE DE HISTORIA DEL EJÉRCITO DEL PERÚ, 2012, p. 19). En un contexto de inestabilidad y de corrupción en el poder político, esta realidad iba acompa- 
ñada de marginación racial y étnica, de desempleo y hambre, así como de explotación y abusos por parte de terratenientes, lo que sentó la base de las oposiciones entre clases sociales. En 1978, un editorial de la Revista Actualidad Militar escribe que «el mundo...se encuentra en crisis integral. Tambalea el campo económico, el campo social, y el campo espiritual. Nuestro país no es una isla; está instalado, precisamente, en este convulsionado mundo» (lbid., p. 14). Así, importantes segmentos de la población peruana vieron en la guerrilla maoista la posibilidad de «poner fin a la larga dominación capitalista impuesta externamente en América Latina y en el Tercer Mundo» (SCOTT PALMER, 2014, p. 132).

Muchas mujeres, principalmente campesinas y obreras, indígenas, negras, mestizas y pobres, pero también estudiantes y profesoras, oprimidas tanto por el patriarcado (estatal, marital y eclesiástico) como por el capitalismo, se juntaron a la labor de resistencia y lucha por sus derechos ciudadanos elementales y contra la violencia del Estado, optando por la "Guerra Popular». Asimismo, en el presente trabajo, utilizo la teoría de la ciudadanía multicultural elaborada por el filósofo político canadiense Will Kymlicka, aplicando aquí su concepto de «formas de ciudadanía diferenciada en función del grupo (étnico o nacional)» (KYMLICKA, 1996, p. 57) al grupo o partido militarizado que fue el «Partido Comunista del Perú» (PCP), también llamado «Sendero Luminoso» (SL)' por sus detractores, heredero del Partido Socialista creado en 1928 por José Carlos Mariátegui. Kymlicka distingue dos tipos de «reivindicaciones» que un grupo podría hacer. El primero se refiere a las relaciones intragrupales designadas como «restricciones internas» en cuanto se pretende "proteger al grupo del impacto desestabilizador del disenso interno» (por individuos que no respetan las reglas del grupo o que «restringen la libertad de sus propios miembros en nombre de la solidaridad de grupo»|, mientras que el segundo se refiere a las relaciones intergrupales designadas como «protecciones externas» en cuanto, -debido a «injusticia entre grupos», aquí entre posición de clase-, se pretende "proteger al grupo del impacto de las decisiones externas» (económicas y políticas del Estado) (lbid., p. 58-59). Como bien lo precisa el autor, «ambos tipos de reivindicaciones no necesariamente van juntas. Algunos grupos... buscan protecciones externas contra la sociedad mayor sin pretender imponer restricciones internas...sobre sus propios miembros» (lbid., p. 60), como en principio fue el caso con el PCP-SL en cuanto a los derechos de las mujeres, aunque, como lo veremos, la praxis fue a veces diferente.

1 En este artículo, se usará la sigla «PCP-SL ». 
De esta manera, busco entender la manera en que esta organización, en función del orden social y económico existente, se forió una identidad política para una transformación de la sociedad y del Estado, y trabajó la articulación entre varias relaciones sociales de poder, queriendo dar a las mujeres, a través del Movimiento Femenino Popular (MFP), herramientas políticas para "emanciparse» junto con y dentro de las clases sociales más oprimidas. En el período actual donde se invoca la importancia de la «memoria», «reconciliación», «justicia»y «perdón», el presente texto, que explora un cierto feminismo revolucionario en el Perú, cuestiona la historiografía feminista existente sobre el conflicto armado peruano. Considerando la ausencia de trabajos escritos sobre el Movimiento Femenino Popular, la única manera de conseguir fuentes primarias es entrevistar a personas que prepararon y/o participaron en la guerra. Entre 2011 y 2016 , en Lima y provincias, hice 28 entrevistas semi-abiertas a mujeres y hombres entre 40 y 75 años de edad, que fueron integrantes del PCP-SL a nivel del «Ejército», «Partido» o «Frente», con o sin condena por «terrorismo». Del conjunto de entrevistas, 26 se realizaron fuera de los penales y 2 en el penal para mujeres de Máxima Seguridad de Santa Mónica en Chorrillos, Lima. Cada entrevista duró entre 2 y 8 horas (en varias sesiones). Las otras fuentes primarias principales se constituyen de: un relato colectivo escrito que me entregaron las prisioneras del PCP-SL en 2013 desde el penal de Chorrillos (en la medida en que no se pudo hacer entrevistas individuales), numerosas conversaciones informales con algunas prisioneras en la carcel, del texto fundador del Movimiento Femenino Popular, el periódico El Diario (donación de Sybila Arredondo a la Biblioteca Nacional del Perú), documentos judiciales del Archivo de la Universidad Nacional San Cristobal de Huamanga (Ayacucho), y testimonios de la Comisión de la Verdad y Reconciliación.

Para alguno.as de mis entrevistado.as, el Movimiento Femenino Popular se fundó en 1965 cuando Augusta Deyanira La Torre Carrasco, nacida en 1945 y quien, siendo hija de un alto dirigente comunista -había sido parte de la Juventud Comunista del Perú a finales de los años 1950, y parte de la guerrilla del «Partido Comunista del Perú» (PCP) en 1965- fue elegida a la presidencia del MFP (ANDREAS, 2004, p. 314), después de su viaje político a China y de la escisión del Partido Comunista entre las líneas pro-China y pro-Rusa en 1964, año en que ella integra la «Facción Roja» del Comité Regional de Ayacucho (partido maoísta «Bandera Roja»), conformada por el filósofo Abimael Guzmán en 1963 con el fin de dirigir el «partido», sin que él haya sido parte de alguna guerrilla. En cambio, para otro.as, el MFP fue creado en 1973 (COMISION DE LA VERDAD Y RECONCILIACION (b), 2003, p. 26; GUZMÁN, IPARRAGUIRRE, 2014, p. 289), cuando Augusta, 
entonces llamada «Camarada Norah», ya era segunda en la jefatura del «Partido Comunista del Perú» (PCP) formado y dirigido a partir de 1970 por Guzmán, devenido «Presidente Gonzalo», con quien se había casado en 1964.

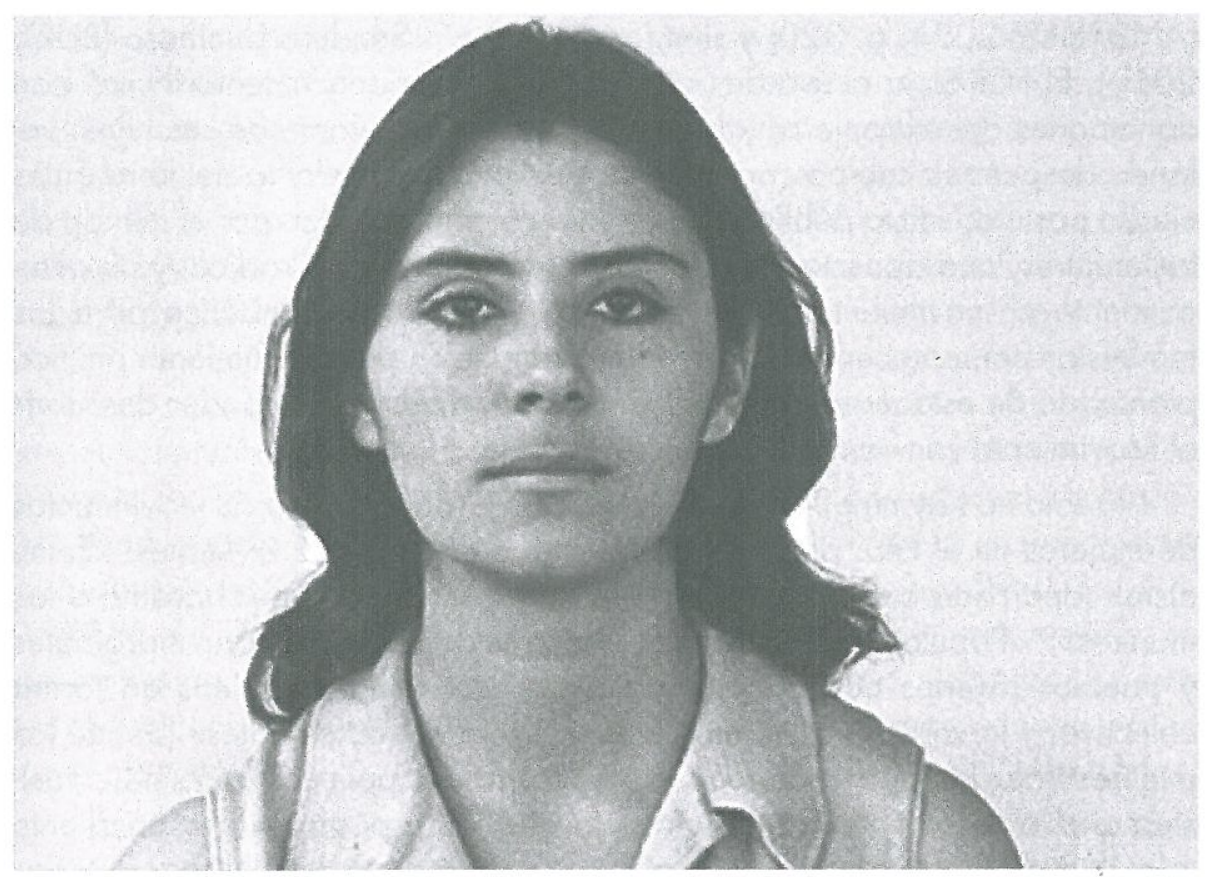

Augusta Deyanira La Torre Carrasco, años 1960-70.

Cualquiera podría pensar que para acercarse al Movimiento Femenino Popular, basta buscar información en los ya conocidos textos académicos feministas peruanos. En ese intento, me interesé en el libro Feminismos en América Latina; Su aporte a la política y a la democracia, publicado en 2008 y cuya autoría es de Virgina Vargas, socióloga peruana conocida por haber fundado la ONG Centro de la Mujer Peruana Flora Tristán. Descubrí que la dedicatoria va dirigida « a María Elena Moyano, por el libro que no llegamos a escribir juntas; y porque sigue manteniéndose como el árbol de la esperanza en nuestros corazones y en nuestras luchas». M.E. Moyano, feminista afroperuana nacida en 1958, fue dirigenta vecinal y presidenta en 1986 de la Federación de Mujeres de Villa El Salvador, una comunidad urbana autogestionada, fundada en 1971 por ochenta familias 
que construyeron sus viviendas en esta zona desértica del Sur de Lima. En los años 1980, en el contexto de los Comedores Populares creados por las mujeres de barrios periféricos más pobres, Villa El Salvador llegó a ser la ciudad del país que recibió más ayuda financiera nacional (de partidos políticos, iglesias, municipalidades) e internacional para apoyar los programas sociales alimentarios. La corrupción fue creciendo a nivel nacional. En 1989, Moyano, una vez teniente alcaldesa de la municipalidad de Villa El Salvador, tuvo que manejar millones de dólares provenientes de ONGs (ANDREAS, 2004, p. 320) y siempre se opuso a Sendero Luminoso (BURT, 2010). El PCP-SL la acusó de "corrupción" y "enriquecimiento ilícito" con donaciones del extranjero, y la asesinó en 1992 delante de sus hijos, volando después su cuerpo con dinamita. Además, el prefacio del libro antes citado postula: «Esta publicación es un recorrido histórico por el mundo de las mujeres, una apuesta en la lucha por la democracia radical y un acercamiento al movimiento de mujeres, cuya figura más simbólica para las feministas peruanas es María Elena Moyano.» Un posicionamiento político planteado de esta manera dejaba entrever la dificultad de poder descubrir el Movimiento Femenino Popular por esta vía.

No solo no hay ninguna mención del MFP en la tipología de movimientos de mujeres en el Perú propuesta por Vargas -con las tres vertientes: «Feminista» (dedicada a «denunciar el sistema sexo-género que subordina a las mujeres»); «Popular» (compuesta por mujeres de barrios urbano-marginales y pueblos jóvenes que buscan satisfacer necesidades básicas en forma colectiva) y la vertiente «De los espacios políticos tradicionales» (donde las mujeres trabajan por sus derechos desde partidos políticos y/o sindicatos)sino que la autora precisa en una nota de pie de página correspondiente a la última vertiente de esa tipología: "Aquí no estoy considerando a todas las mujeres que tienen un compromiso político con partidos y sindicatos, no solo porque algunas no están ni siquiera mínimamente identificadas con los asuntos de la mujer, sino también porque sus prácticas sociales apuntan en otra dirección. La expresión más extrema son las mujeres de Sendero Luminoso, que tienen la más tradicional y autoritaria de las concepciones sobre la política.» (VARGAS, 2008, p. 36). El desencuentro se hace más evidente cuando la autora escribe (también en una nota de pie de página) que "Sendero Luminoso, en el colmo del dogmatismo, nos acusa de ser feministas burguesas que tratan de evitar que las mujeres populares tengan hijos para apoyar la revolución» (lbid., p. 74).

Este trabajo tiene por lo menos el mérito de ver a las mujeres del PCP-SL con un «compromiso político», lo cual no se reconoce desde los diferentes gobiernos. En 1993, la feminista peruana Maruja Barrig recuerda también que éstos últimos y sus Fuerzas Armadas incurrieron en el error de conside- 
rar el accionar de «SL» como un «problema delicuencial y luego militar», lo cual es para ella un «error en el tratamiento de un fenómeno político, enraizado en las seculares postergaciones sociales y económicas de importantes sectores de la población» (BARRIG, 1993, p. 101). Sin embargo, si bien la autora coloca la actividad de las mujeres de «SL» dentro de la «actuación pública femenina», opera una separación, al igual que Vargas, entre la vertiente «popular» (urbano-marginal) representada por «líderes comunales», y «las jóvenes senderistas» (lbid., p. 97). Plantea que hubo «dos propuestas radicalmente distintas: la organización entorno a la sobreviviencia y el consumo colectivo» (por organizaciones femeninas urbano-populares a través de la creación de comedores comunales con donaciones del gobierno central y local, ONGs, parroquias y agencias internacionales de desarrollo), «y la militancia alrededor de un líder, Abimael Guzmán, quien solicitó a sus seguidores la destrucción del Estado para construir una nueva sociedad» (lbid. p. 90), lo cual parece ser una falsa dicotomía a la luz de los testimonios recogidos. Además, una parte de esta literatura feminista se dedica a psiquiatrizar a las mujeres de «SL», suponiendo que «frustración», «resentimiento», «locura», «fanatización», «alienación», «rencor», «odio» y «furia» les conducirían a integrar el grupo, así como su «desvalorización» (de «pertenencia de género») y «sumisión» como mujeres (a un líder «todopoderoso») dentro de la organización (BARRIG, 1993, pp. 99-103; KIRK, 1993, p. 17; VILLANSANTE CERVELLO, 2012, p. 10). De esta manera, se deslegitimiza, se estigmatiza, se invisibiliza y se objetifica sistematicamente las experiencias situadas de sujetos políticos que escogieron una lucha de corte maoísta.

Como lo afirma el politólogo francés Jacques Sémelin, trabajar sobre masacres implica dificultades a nivel moral, psicológico e intelectual: moral porque se necesita encontrar la distancia correcta para hablar de un conflicto políitico; psicológica porque no es facil investigar sobre hechos que pueden inspirar repulsión; e intelectual porque toda guerra desafía el entendimiento y es a veces explicada por la «locura humana» (SÉMELIN, 2005, p. 63). Pese a esas dificultades, a la hora de analizar la historia del PCP-SL y sus componentes, resulta fundamental considerar la naturaleza política de la insurgencia sin objetificar a sus integrantes. Aquí entran en juego la metodología y la perspectiva epistemológica de los y las investigadores.as, en particular su posicionamiento político, su sexo, su etnicidad y nacionalidad. Así nos inspire horror el asesinato de M.E. Moyano, la investigación feminista es la que menos debería negar, silenciar o estigmatizar lo que fue el Movimiento Femenino Popular. La mayoría de las investigadoras peruanas academicamente privilegiadas y especializadas en estudios de género ly a menudo cercanas a ONGs nacionales y finan- 
cieras extranjeras), no solo no consideran la experiencia del MFP como tema de investigación, sino que contribuyen activamente a la construcción social del enemigo político, alimentando una historiografía parcial y hegemónica, con la excepción de trabajos que se interesan en el discurso del MFP para finalmente deslegitimarlo (HENRÍQUEZ AYÍN, 2006, pp. 20-21; LÓPEZ, 2012).

Mientras esta producción científica, muy cercana al discurso oficial sobre el conflicto armado, ha obviado o distorsionado una parte de la historia de los movimientos populares de mujeres, es tornándose hacia trabajos realizados por ciertas académicas extranjeras, peruanas radicando en el extranjero, que uno puede observar una ruptura epistomológica y acercarse a un entendimiento contra-hegemónico de la historia de las mujeres del PCP-SL. Tal es el caso con la investigadora norteamericana Carol Andreas, quien fue profesora en la Universidad Central de Huancayo en los años 1970 y 80 , y relató con empatía y fineza lo que significó el MFP en su libro When Women Rebel: The Rise of Popular Feminism, publicado en 1986 y aún no traducido al español. Además, los trabajos de la linguista brasileña Mónica Cruvinel $(2014 ; 2015)$ sobre el arte como práctica de resistencia entre las prisioneras políticas, de la antropóloga catalana Caty Canyelles (2012) (no publicado) sobre lo que significa «Ser mujer y revolucionaria», de la socióloga española Marta Romero (2016) con " Las 'otras' olvidadas», y de la criminóloga peruana Maritza Felices-Luna (1999; 2007), profesora en la Universidad de Ottawa (Canadá), sobre «la implicancia de las mujeres en la lucha armada como práctica ciudadana», son de primera importancia en la construcción de una nueva historiografía de las mujeres insurgentes en el conflicto armado peruano. Tienen en común el hecho de que su acercamiento académico no es de objetificación, ni contiene una dinámica de poder y de separación entre investigadora y participante. Pasa lo mismo con el sociólogo peruano Rodolfo Dynnik Asencios (2013), cuyo trabajo sobre «las motivaciones y militancia de jóvenes encarcelados de Sendero Luminoso en Lima (1989-1992)», es una excepción en la medida en que cuestiona en parte la producción peruana hegemónica del saber sobre el conflicto. Otras nuevas perspectivas críticas están apareciendo, como se ha visto en 2014 durante el primer coloquio internacional sobre género y violencia política², que se llevó a cabo en Ayacucho (GUINÉ, 2014). Quiero tambien citar el trabajo pionero sobre Augusta La Torre de Jaymie Patricia Heilmann (2010a), profesora de historia latinoamericana 
en la Universidad de Alberta (Canadá), quien me hablaba hace poco de la gran importancia de explorar el tan poco conocido Movimiento Femenino Popular.

Para entender el surgimiento del MFP, es necesario tener presente el contexto internacional y nacional de los años 1940-1960 a nivel económico y político. Después de haber obrado, desde los años 1940, por la recuperación de tierras ocupadas por terratenientes y gamonales, las luchas campesinas desarrollan el movimiento de invasión de tierras con una fuerte movilización en 1963 y 64 que se acompaña de la lucha contra el hambre, la desnutrición, la importación de productos alimenticios, la desocupación, el alto costo de vida y la represión del Estado. Las guerrillas peruanas de los años 1960 tuvieron influencia castrista o trotskista a través, por ejemplo, del Movimiento de Izquierda Revolucionaria (MIR), el Ejército de Liberación Nacional (ELN), el Frente de Izquierda Revolucionaria (FIR) y los guerrilleros de Jauja. Se realiza también el movimiento de los trabajadores en los años 1967 y 68, con numerosas huelgas de obreros que fortalecen la Central General de Trabajadores del Perú (CGTP), la lucha de los maestros quienes crean el Sindicato Único de Trabajadores de la Educación Peruana (SUTEP), así como las luchas de las juventudes universitarias y secundarias. En 1969, en Ayacucho, el campesinado se junta con las poblaciones urbano-marginales, las mujeres y los jóvenes (rurales y semi-urbanos) para la lucha por la educación y la gratuidad de la enseñanza. Según A. Guzmán: "La causa de este desarrollo del movimiento de masas es la existencia de situación revolucionaria», que se produce, de acuerdo a Lenin, cuando «los de abajo no quieren seguir viviendo como antes y los de arriba no pueden seguir administrando y gobernando como hasta entonces» (GUZMÁN, IPARRAGUIRRE, 2014, p. 155).

La promulgación de la ley de la reforma agraria por el General Velasco a partir de 1969, se inscribe en los objetivos planteados en la Conferencia de Punta del Este en 1961 en aras de la Alianza para el Progreso ideada por el Presidente J. Kennedy para controlar América Latina e impedir una posible influencia de la revolución cubana en la región (ALLENDE, 1967). En los años 1970, una parte del movimiento campesino se opone a la reforma agraria, empezando, como en el caso de la Federación Departamental de Campesinos de Cajamarca (FEDECC), a «reclamar la entrega de todas las tierras y a rechazar el pago de la deuda agraria», así como pedir «mayor independencia frente al gobierno» (MONGE, 1989, p. 80). Según el historiador Carlos Monge, en 1974, los acuerdos de la convencion de la FEDECC «formalizaron la ruptura con el proyecto reformista del gobierno y estimularon un vasto movimiento de tomas de tierras. Desde ese momento las relaciones entre el campesinado y el Estado fueron de conflicto» (MON- 
GE, 1989, p. 70). Si bien la reforma se aplicó sin mayores dificultades en la región de Cuzco, la oposición al proyecto reformista se extendió a varias partes del país, principalmente Piura y Andahuaylas, lo cual hizo desplegar la represión militar contra los dirigentes campesinos. Dentro del movimiento campesino, el resultado fue el surgimiento de varias corrientes de izquierda con múltiples desacuerdos internos. Si bien la reforma tenía que implementarse en 10 años con el objetivo de eliminar el poder terrateniente, hacia 1982, el 17\% de las demandas campesinas conciernen su oposición a los gamonales que intentaban recuperar tierras, mientras que el $37,50 \%$ de las demandas al Estado son "contra la corrupción y el abuso» de la administración pública, y el $25 \%$ "contra la represión» del Estado (lbid. pp. 80-82). Además, no son respetados los derechos del campesinado a expresarse y organizarse libremente. La «lucha armada» desatada por el PCP-SL en 1980, y la respuesta contrasubversiva de las Fuerzas Armadas, fragilizaron aún más los derechos de las organizaciones campesinas (lbid. pp.82-83).

En cuanto a las mujeres, el texto de ley de la reforma y los discursos del General Velasco sobre ésta, serán compuestos en clave exclusivamente masculina, excluyendo del proceso a las campesinas:

De hoy en adelante, el campesino del Perú no será más el paria ni el desheredado que vivió en la pobreza...y que miró impotente un porvenir igualmente sombrío para sus hijos...el campesino del Perú será en verdad un ciudadano libre a quien la patria, al fin, le reconoce el derecho a los frutos de la tierra que trabaja, y un lugar de justicia dentro de una sociedad de la cual ya nunca más será, como hasta hoy, ciudadano disminuido, hombre para ser explotado por otro hombre... La tierra debe ser para el campesino, para el pequeño y mediano propietario; para el hombre que hunde en ella sus manos...para el hombre, en fin, que lucha y enraíza su propio destino en los surcos fecundos... Creemos cumplir así un verdadero deber de reparación para todos aquellos campesinos olvidados del Perú, hombres que centenariamente han sufrido el castigo de todas expoliaciones... Al hombre de la tierra ahora le podemos decir en la voz inmortal y libertaria de Túpac Amaru: " ${ }_{i}$ Campesino, el patrón ya no comerá más de tu pobreza! (VELASCO, 1969).

Asimismo, en el texto de ley, el artículo $84^{\circ}$ de la parte dedicada a las «adjudicaciones» especifica que «Para ser admitido como postulante para la adjudicación de unidades Agrícolas Familiares, se requiere: ser perua- 
no; ser jefe de familia; ser campesino; no ser propietario de tierras...» (VELASCO ALVARADO et. al, 1971, p. 40). A nivel de herencia, el artículo $88^{\circ}$ plantea: "Cuando falleciera el adjudicatario de una unidad agrícola familiar sin haber cancelado su precio...la Dirección General de Reforma Agraria y Asentamiento Rural adjudicará gratuitamente la misma a la cónyuge o compañera permanente y a los hijos menores de dieciocho años, quienes estarán obligados a liquidar el condominio cuando el último de los hijos cumpla dieciocho años de edad, o adquiera capacidad civil» (Ibid., p. 41). Según la socióloga peruana Blanca Fernández Montenegro, «En esa historia, las mujeres estuvieron casi desaparecidas» (FERNÁNDEZ MONTENEGRO, 2010 , p. 15). Solo el $5 \%$ de las mujeres fueron beneficiarias de la reforma. "A algunas se les permitía participar en las asembleas en representación de sus hijos varones menores. Ellas iban para «hablar por el chiquito» (el hijo varón de un campesino fallecido) que en cuanto cumpliera los 18 años iba a acceder a la cooperativa. Y la madre? preguntamos. Pues el hijo la mantendrá, era la respuesta. ¿ Trabajar con las mujeres, para quée, si ellas no saben nada, son ignorantes, fue una de las primeras afirmaciones de algunos dirigentes» (lbid.). Así, a pesar de la creación, en 1974, de la Comisión Nacional de la Mujer Peruana y de la «Primera Reunión de la Mujer Campesina y Centros Fabriles» como parte de la reunión de la Confederación Nacional Agraria (CASAFRANCA, 1996, p. 50), la reforma no contempla a las mujeres como trabajadoras ni como beneficiarias. Además, se ven atribuidas las tierras de peor calidad en caso de acceso a parcelas, no pueden votar en asambleas comunales, y con mucha dificultad ser elegidas como dirigentas comunales (lbid., pp. 53-54). Por otro lado, a partir de 1978, las mujeres pobres de Lima se organizan entorno a las necesidades básicas, principalemente alimentación, constituyéndose en "comedores populares autogestionados» a raíz de ollas comunes que se habían formado durante la huelga nacional de protesta popular (BEBBINGTON, SCURRAH, BIELICH, 2011, p. 302). Las organizaciones de mujeres habían sido las principales organizaciones sociales que se habían formado en los años 1960 y 1970 en respuesta al crecimiento demográfico y los problemas de pobreza que se habían dado con las migraciones internas de clases populares desde el campo hasta la periferia de Lima (Ibid. p. 285). Dentro del «movimiento de mujeres urbano-populares», se distinguen tres organizaciones: los comedores populares, los clubes de madres y los comités de Vaso de Leche (Ibid. p. 289). Los comedores populares fueron autónomos o dependientes del Estado, de la Iglesia y de ayudas internacionales. El primer comedor popular autogestionado se forma en 1978 en el distrito de Comas (suburbio de Lima) (lbid. p. 292-293). 
Es en este contexto de exclusión y escasos derechos para las campesinas -por «las medidas fascistas» de Velasco según el PCP-SL (PARTIDO COMUNISTA DEL PERÚ, 1988), aunque esta reforma fue implementada con una fuerte tendencia de izquierda progresista- $y$ de luchas contra la pobreza desde las organizaciones de mujeres urbano-populares, que el Movimento Femenino Popular se va desarrollando en los años 1970. Guzmán escribe:

Las mujeres son parte ardorosa y resuelta en todos los frentes de lucha popular...las obreras firmes y tenaces en las huelgas; y las admirables mineras, sólido apoyo con sus «comités de damas»...las campesinas...desde antiguo decidiendo en las asambleas comunitarias, concretando tareas, invadiendo tierras, marchando en primera fila y siempre prestas al choque con la represión, y con su sangre, sus manos y sus dientes hechos armas desarmando policías. Y las maestras, profesionales diversas y universitarias, jóvenes intelectuales forjadas y templadas en luchas constantes e ideas nuevas de cuyas filas ha salido una legión luminosa de revolucionarias, honra y prez de nuestro pueblo. Así el movimiento femenino reinició su camino como parte inseparable que es del movimiento popular (GUZMÁN, IPARRAGUIRRE, 2014, pp. 152-153).

Por lo contrario, el antropólogo peruano Carlos Ivan Degregori habla de la «impresionante transformación de las jóvenes...: protegidas por sus compañeros varones en 1969, comandantes guerrilleras o integrantes de "comandos de aniquilamiento" veinte años después." (DEGREGORI, 2007, p. 123). Y si bien afirma que "el grado y las formas de participación femenina en los movimientos sociales están todavía en gran medida por estudiarse", no explora el Movimiento Femenino Popular, ni ahonda en las relaciones que se tejieron a partir de finales de los años 1960, entre las mujeres de varios sectores educativos y el MFP. Así, la historiografía dominante, cuando no invisibiliza el MFP, lo aisla de otros movimientos sociales de la época donde las mujeres jugaron un papel de primera importancia y de donde salieron mujeres integrantes del PCP-SL.

La semilla del Movimiento Femenino Popular se encuentra en la Fracción Femenina del Frente Estudiantil Revolucionario (FER), formada en Ayacucho en 1963-64, en particular por Augusta La Torre, junto con universitarias feristas. Organizaron una escuela de cuadros para el FER, dándole una base ideológica y política donde por primera vez se evoca, en vista de crear un "movimiento femenino", la tesis marxista (o "principio proletario") de la "emancipación de la mujer" en base a su doble opresión (por el patriarca- 
do y el capitalismo). Para este fin, las feristas formaron grupos de mujeres: campesinas, obreras, jefas de hogar, estudiantes, profesionales, barriales, pobres (GUZMÁN, IPARRAGUIRRE, 2014, p. 288). Estuvieron presentes en todo el país: fábricas, barriadas y universidades en las ciudades, así como cooperativas azucareras, comunidades y centros mineros en el campo (lbid., 2014, p. 386). La Declaración de Principios y el Programa del FER de Ayacucho (también atribuidos al MFP) se publican en quechua y en español en el $n^{\circ} 2$ de su vocero: Rimariyña Warmi (Habla Mujer) en 1973. Plantea la "movilización clasista" de las mujeres (alrededor de la "Revolución Peruana, antiimperialista y antifeudal"); la lucha contra la opresión de las mujeres (en lo económico, político e ideológico); el cumplimiento, la defensa y la ampliación de derechos para las mujeres; la movilización política de las mujeres con "propaganda y agitación" en base al Pensamiento de Mariátegui; la formación de una "conciencia clasista" para "servir el pueblo" y "ligarse a las masas" para luchar por sus derechos; el combate por la formación de la Federación Nacional de Mujeres del Perú y del Socorro Rojo (luego conocido como Socorro Popular); la creación de un órgano de prensa que sea "expresión clasista" de las mujeres; la construcción de alianzas con las mujeres del "Frente Revolucionario Mundial" y con los pueblos oprimidos que luchan contra el "imperialismo norteamericano" y el "revisionismo soviético". Guzmán afirma: "Desde sus inicios, el que con el correr del tiempo devendrá Movimiento Femenino Popular, desde sus antecedentes como Fracción Femenina del FER, surgió y se desenvolvió bajo las banderas del proletariado enarbolando la divisa proletaria de la emancipación de la mujer" (GUZMÁN, IPARRAGUIRRE, 2014, p. 289). Cabe señalar que desde la mitad de los años 1960, la hacienda Iribamba de los padres de Augusta La Torre, ubicada en el Distrito de Luricocha (Provincia de Huanta, Departamento de Ayacucho), era el centro de actividades políticas. En junio 1970, la policía arresta ahí a varios miembros como Guzmán y Osmán Morote (parte del Comité Central) por "subvertir la reforma agraria" (HEILMAN, 2010b, p. 186).

El Movimiento Femenino Popular fue concebido e impulsado por Augusta La Torre como parte del "activismo revolucionario" que precede toda guerra (KAMPWIRTH, 2003). Dentro de la línea política general del PCP$\mathrm{SL}$, la llamada "línea de masas" contempla la "organización de las masas" a través de la creación de "organismos generados" definidos en 1973 como "Los movimientos propios como organizaciones generadas por el proletariado en los diferentes frentes de trabajo" (PARTIDO COMUNISTA DEL PERÚ, 1988) (es decir "organismos de masas"), aplicando la experiencia china de "trabajo abierto" y "trabajo secreto", y sentando las bases para la "lucha armada" que empezó en 1980. Los principales Organis- 
mos Generados fueron el Movimiento de Obreros y Trabajadores Clasistas (MOTC), el Movimiento de Campesinos Pobres (MCP); el Movimiento Clasista Barrial (MCB); el Frente Estudiantil Revolucionario (FER); el Frente Revolucionario Estudiantil Secundario (FRES), y el Movimiento Femenino Popular (MFP).

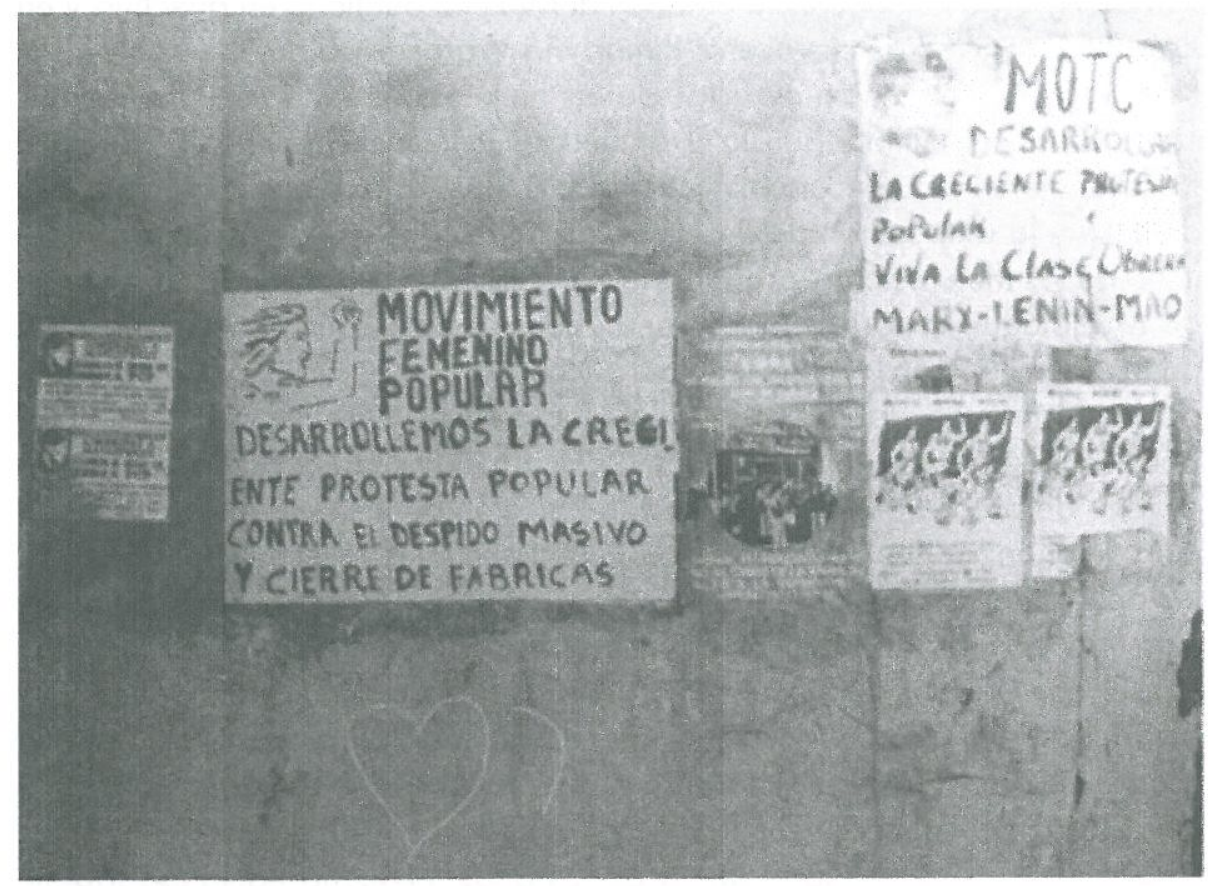

Cartel del Movimiento Femenino Popular, extraído del libro de Carol Andreas, When Women Rebel. The Rise of Popular Feminism in Peru, 1986.

Uno de mis entrevistados, que llamaré Javier, comenta que:

Augusta es la parte más consecuente de ese aparato y es la que demuestra mayor firmeza y fidelidad a los principios. Concretamente, en todas las organizaciones, como asociaciones de barrios, por ejemplo, se arman secciones femeninas y luego esas secciones entran a juntarse en el Movimiento Femenino Popular...Lo que hacía Augusta era tomar a las mujeres más aguerridas (es decir las más pobres), las educaba y las integraba al movimiento. Armamos la sección femenina del FER, luego la sección femenina de la federación de hogares, luego la sección femenina del frente de defensa del 
pueblo, luego la sección femenina de las trabajadoras del mercado, la sección femenina de la federación de campesinos de Ayacucho, etc...y con todas ellas se armaban las convenciones de mujeres.

Se atendía primero sus necesidades básicas, problemas de agua, desagüe, luz, lucha por la tierra, en la medida en que se trabajaba con las mujeres más pobres. En ese proceso de juntarlas y educarlas contra la doble opresión, "había resistencia de los varones", dice Javier. Pero la idea era hacer entender a las mujeres que "no basta con que se pongan bravas contra el marido". "Lo que tienen que hacer ellas es integrar al marido en la lucha" (contra la feudalidad patriarcal y por mejores condiciones de vida) "y eso les va a hermanar más bien. Va a llevar a que el marido también la respete. Va a menguar un tanto el menosprecio del marido por la mujer". Pero a veces en las asambleas habían choques entre marido y mujer, lo cual seguía en casa cuando el hombre sentía que su mujer le había "bajado la autoridad" en público. Javier cuenta: "Esos líos hemos tenido que ir a resolver. Augusta iba a la casa, hablaba con ambos y con los hijos para ir limpiando asperezas, o sea, irlos elevando a ambos. Esa era una de sus tareas." Muchas veces la mujer priorizaba el problema del agua mientras que el varón daba prioridad a la luz.

¿El varón para que quería luz? Para que mañana tenga su televisor. ¿la mujer para qué quería el agua? Para facilitarle su cocina. Esas contradicciones teníamos que resolver y el marido tenía que dar prioridad al agua y dar la razón a su mujer. Augusta y otras mujeres del MFP también trabajaron en las zonas mineras para integrar a la mujer del obrero a los sindicatos obreros y a las huelgas mineras. $Y$ hubo lucha fuerte porque muchos mineros no querían.

Según una ex combatiente del PCP-SL que llamaré Isabel: "Augusta y las mujeres del MFP iban a los mercados y a los barrios para explicar la emancipación de las mujeres. Augusta les bajaba la línea, a lo más profundo de las masas. Era muy querida por el campesinado". Otros dijeron de elle que era "de convicciones apasionadas y deciciones definitivas" (HEILMAN, 2010a, p. 166).

Javier recuerda que en sus charlas, Augusta y el conjunto del MFP retomaban las tesis marxistas de Mariátegui sobre las mujeres, así como citaban a Flora Tristán y Clorinda Matto de Turner. Después de Ayacucho, las mujeres del MFP irán a Cerro de Pasco, también a Cajamarca y La Libertad, entre otros. El Movimiento Femenino Popular organizó su primera 
Convención de mujeres campesinas de Ayacucho en 1974. El movimiento recogía fondos según el principio de "autosostenimiento". "Las masas nos sostenían", cuenta Flor, otra ex militante. En 1974, Augusta La Torre decide ir a Lima con Guzmán para "desarrollar el partido" desde la capital y organizar varias convenciones de mujeres. Ambos se instalan entonces en la casa de los padres de Augusta en el barrio de Jesus María. Ese mismo año, se da la Convención de Universitarias de Lima sobre la emancipación de la mujer. Pero la mayor actividad del movimiento se da en 1975, por ser el año internacional de la mujer proclamado por las Naciones Unidas, con 5 grandes eventos: la Asamblea nacional de mujeres, la 1ra Convención nacional del MFP, la Convención de mujeres obreras, la Convención de mujeres pobres de barrios y barriadas de Lima, y la Convención nacional de universitarias sobre emancipación de la mujer. En 1975, empieza la "segunda fase" del Gobierno Revolucionario de las Fuerzas Armadas, con un golpe de Estado contra Velasco por el entonces Ministro de Guerra, Francisco Morales Bermudez. En 1976, año de importantes movilizaciones sociales en todo el país, el MFP organiza tres eventos, la Convención de mujeres pobres de barrios y barriadas de Tacna, la Convención de mujeres de Chiclayo, y la campaña de propaganda masiva con la difusión de 70.000 volantes "A las madres del pueblo combatientes ignoradas" en el Día de la Madre. En 1977, el gobierno de Bermúdez convoca a elecciones en vista de la Asamblea Constituyente que será efectiva en 1978. La nueva Constitución es promulgada en 1979, año en el que se convoca a elecciones presidenciales para el 18 de mayo de 1980. El PCP-SL participa en la huelga magisterial de 1978 y en la huelga estudiantil de 1979 (CVR (a), 2003 , p. 22). A finales de la década del 70 , se dan la llamada "Reconstitución del Partido Comunista del Perú" -por lo cual el MFP y el FER se vuelven base para esta reconstitución en Lima- así como la decisión de iniciar la "lucha armada" el día de las elecciones en 1980, desde el campo, en el pueblo de Chuschi (Provincia de Cangallo, Departamento de Ayacucho), con la quema de ánforas. Augusta La Torre pasa a la clandestinidad en 1979, es decir que se "liga a las masas que la ocultan". ${ }^{3}$

Hay que señalar que si bien el Movimiento Femenino Popular se construyó a partir de las secciones femeninas de varias organizaciones, organismos generados como por ejemplo el Movimiento Clasista Barrial (MCB) antes citado, se fue construyendo a través de la acción del FER y del MFP en los barrios y barriadas de Lima (GUZMÁN, IPARRAGUIRRE, 2014, p. 
388). Así, si bien muchas mujeres de las organizaciones urbano-populares dedicadas a los comedores populares de Lima se opusieron y lucharon contra el PCP-SL en los años 1980 y 1990 (BLONDET, 1996), cabe resaltar que muchas de ellas decidieron ser parte del MFP, aunque más en provincia que en Lima, pero no se ha investigado sobre este tema desde la academia. En Ayacucho, desde los años 1960, hubo fuerte interacción entre organizaciones populares de mujeres como los Clubes de Madres y las estudiantes marxistas y mariateguistas de la Facultad de Trabajo Social de la Universidad Nacional San Cristobal de Huamanga (UNSCH) (ROJAS ALLENDE, 2003, pp. 46-47), lo cual podría dejar suponer que algunas asistentes sociales eran parte del MFP. De la misma manera, hay que mencionar que algunas campesinas como por ejemplo Barnabela Cisneros y Estela Salvatierra emergieron en los años 1970 como dirigentas en calidad de secretarias generales del MFP en comunidades de Ayacucho ${ }^{4}$, a raíz de las convenciones antes mencionadas. Guzmán, refiriéndose al MFP, explica que el PCP-SL "construyó uno de los organismos generados que más ha servido al Partido...y el empeñoso esfuerzo y energías que su plasmación demandaba, redundo en resultados inmensamente mayores que las más altas expectativas imaginadas, lo prueba su grandioso aporte a la guerra" (GUZMÁN, IPARRAGUIRRE, 2014, p. 387). De hecho, según Carol Andreas: "Mientras investigué sobre las organizaciones de mujeres en las partes pobres del Perú, descubrí que Sendero Luminoso había atraído a muchas más mujeres que hombres." (ANDREAS, 1990/91, p. 20).

El Movimiento Femenino Popular tendrá su canto titulado "Luchadoras de la revolución". Aquí una de las versiones de su letra:

Mujeres obreras campesinas / luchadoras de la revolución / frente altiva del pueblo combatiente militantes del frente de Lenin. Nuestra vía es la lucha armada / contra el hambre y la explotación. / Venceremos al vil imperialismo / la victoria es del pueblo y su fusil / Movimiento femenino popular / Movimiento femenino popular / Campesinos de la tierra del ande / propietarios de las tierras del sol / el arado será tu herramienta / luminoso sendero transitamos I en los campos de lucha por la paz / Proletario de las filas obreras / militantes del frente de Lenin / con tus manos se mueve el engranaje y en tu pecho grita la libertad / Movimiento femenino popular / Movimiento femenino popular / Mujer combatiente tu que sirves /

4 Entrevista con Ana María, ex integrante del MFP y PCP-SL, julio 2012. 
al pueblo de todo corazón / en tus manos se agita la bandera / la bandera de la revolución. / Presidente Gonzalo es el guía / con que pueblos del mundo triunfarán / lucharemos sin tregua hasta el final / Movimiento femenino popular / Movimiento femenino popular.

La "lucha de dos líneas" (como expresión de lucha de clases) estuvo también presente en el MFP, especialmente cuando en 1975 se crea en Lima el Centro Femenino Popular (CFP) bajo la tesis de "liberación de la mujer", considerada como "burguesa" porque se piensa que opone hombres y mujeres, lo cual llevó a luchar internamente para que domine el principio de "emancipación de la mujer" (considerado como "proletario" porque contribuye "al proceso revolucionario democrático-nacional." (MOVIMIENTO FEMENINO POPULAR, 1974, p. 7). Según el testimonio colectivo que me entregaron en 2012 las prisioneras políticas del PCP-SL desde el penal de máxima seguridad de Santa Mónica en Lima: "La constitución del MFP enfrentó una aguda lucha interna entre las posiciones proletarias de la fracción roja de Ayacucho y las posiciones del liquidacionismo de 'izquierda'" que "preconizaba la destrucción del Partido" y que "el MFP fuera un organismo autónomo sin dirección partidaria, usando a Mariátegui pero convirtiéndolo en un intelectual burgués, todo lo que era ajeno a los principios marxista-leninista-maoísta sobre la cuestión femenina, es decir opuso la tesis burguesa de la liberación femenina a la tesis marxista de la emancipación de la mujer. Esta línea no proletaria predominó en la constitución del Centro Femenino Popular (CFP). Pero al desarrollarse la lucha interna, el Centro pasó a convertirse en un movimiento femenino clasista, es decir dirigido por el proletariado; precisamente con este movimiento se realizaron diversas convenciones de mujeres".

El resultado de este "deslinde" fue en 1974 la publicación -por el CFP, a 5000 ejemplares y en edición de bolsillo- del documento en tres capítulos "El marxismo, Mariátegui y la emancipación de la mujer" (con una reedición a cargo de las Ediciones Bandera Roja en 1975), preparado por una docena de mujeres aliadas a Augusta La Torre y su proyecto político, dentro del contexto del "Año Internacional de la Mujer" (1975).

Si bien el texto se basa en los aportes de Marx, Engels, Lenin y Mao sobre la opresión de las mujeres, reafirma principalmente la necesidad de utilizar el concepto de "feminismo proletario" planteado por Mariátegui para el Perú, quien había establecido en 1924 una distinción entre "feminismo burgués", "feminismo pequeño burgués" y "feminismo proletario" 5 (MARIÁTEGUI, 1924). El PCP-SL tendrá presente el feminismo y esta distinción en su órgano de prensa El Diario, hasta finales de los años 1980. 


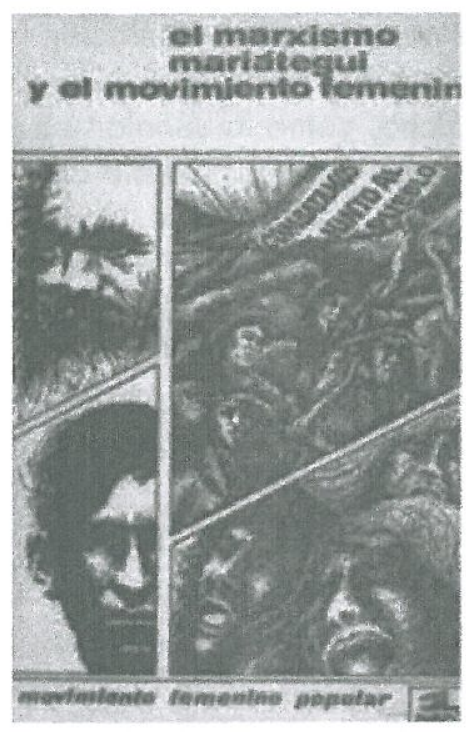

Carátula original del libro "El marxismo, Mariátegui y el Movimiento Femenino", 1974.

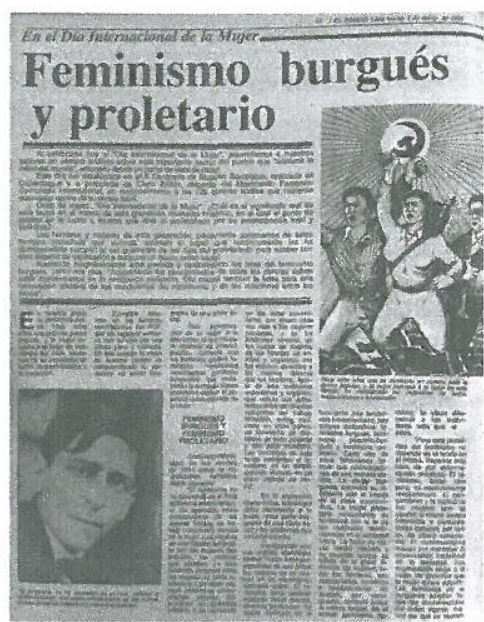

El Diario, 8 de marzo de 1988, Lima.

El MFP plantea:

Qué tipo de movimiento femenino impulsar?... La respuesta es una y concreta: un movimiento femenino popular verdadero no puede construirse y desarrollarse sino desde la posición de la clase obrera, desde el marxismo, y como parte del movimiento popular de cuya liberación depende la emancipación de la mujer...sólo adhiriéndose a la política de Mariátegui sobre la emancipación de la mujer en particular, será posible crear organizaciones femeninas y secciones femeninas en los organismos de masas, como indicara el Amauta para los sindicatos, que fortalezcan y desarrollen las organizaciones de las masas y sirvan a la unidad combatiente del pueblo (MOVIMIENTO FEMENINO POPULAR, 1974, p. 7).

5 Mariátegui precisa: "Cada uno de estos feminismos formula sus reivindicaciones de una manera distinta. La mujer burguesa solidariza su feminismo con el interés de la clase conservadora. La mujer proletaria consustancia su feminismo con la fe de las multitudes evolucionarias en la sociedad futura. La lucha de clases -hecho histórico y no aserción teórica- se refleja en el plano feminista. Las mujeres, como los hombres, son reaccionarias, centristas o revolucionarias. No pueden, por consiguiente, combatir juntas la misma batalla. En el actual panorama humano, la clase diferencia a los individuos más que el sexo." 
De primera importancia es también el llamado a la politización y organización de las mujeres para que puedan luchar por su propia emancipación dentro de la lucha de clases. De hecho, como lo señalan en 1973: "La lucha de la mujer pervana es parte de la lucha del pueblo oprimido y explotado" (MOVIMIENTO FEMENINO POPULAR, 1974, p. 2), lo cual es un posicionamiento político aún vigente hoy día entre las feministas marxistas, como en el caso de la filósofa italiana Silvia Federici, quien escribe en 2010: "El género no debería ser considerado una realidad puramente cultural sino que debería ser tratado como una especificación de las relaciones de clase...la "historia de la mujeres" es la "historia de las clases" (FEDERICl, 2010, pp. 26-27).

Sin embargo, quiero aquí señalar tres puntos. Primero, sobre el origen de la opresión de las mujeres, el MFP sigue a Engels en cuanto esta opresión, así como la explotación de clase, se originarían en la propiedad privada de los medios de producción, pero está demostrado desde la antropología marxista que la dominación masculina ya existía en las sociedades preclasistas y $\sin$ Estado, que no conocían la propiedad privada (TRAT, 1997, p. 3). Segundo, al escribir, siguiendo a Marx, que "el desarrollo del capitalismo va a incorporar a la mujer al trabajo dando bases, condiciones para que pueda desarrollarse; así como la incorporación al proceso productivo las mujeres tendrán la posibilidad de unirse más directamente a la lucha de clases y a la acción combatiente" (MOVIMIENTO FEMENINO POPULAR, 1974 , p. 4), según mostró Federici, no se toma en cuenta el hecho de que la acumulación del poder capitalista se ha hecho también con el trabajo no asalariado de las mujeres (FEDERICl, 2010, p. 23). Tercero, el MFP acepta la tesis de Engels según la cual "en la comunidad primitiva sobre una división natural del trabajo basada en la edad y el sexo, los hombres y las mujeres desenvolvían sus vidas en una espontánea igualdad y participación de la mujer en las decisiones del grupo social" (MOVIMIENTO FEMENINO POPULAR, 1975, p. 17), pero se demostró ulteriormente que las mujeres nunca fueron ausentes de las tareas productivas en agricultura (cosecha), caza de animales o artesanía (TRAT, 1997, p. 4), cuestionando de esta manera la visión naturalizante de la división sexual del trabajo entre hombres y mujeres en la obra de Engels.

Según Andreas, una de las razones por las cuales las mujeres fueron atraídas por el MFP, es que "el PCP-SL ponía énfasis en la autonomía (financiera) y la economía de subsistencia, mientras que la izquierda llamada "revisionista" basaba su modelo económico en las exportaciones. Y dado que las mujeres andinas son las primeras participantes en la economía de subsistencia y que son excluidas de los beneficios del "desarrollo", en esa época, muchas integraron el MFP." (ANDREAS, 1990/91, p. 22). Siempre según la autora: 
El MFP de Sendero insistía en que 'la cuestión de la mujer' no era 'una contradicción secundaria' que podía ponerse de lado hasta después de la revolución. Mientras las integrantes nunca se vieron a sí mismas como la vanguardia de una lucha de clase contra los varones, el movimiento pareció ser una respuesta radical a la super-subordinación de las mujeres indígenas a lo que sus representantes llamaban una 'sociedad semi-feudal y semi-colonial'. Abimael Guzmán y Augusta la Torre nunca abandonaron el énfasis sobre la igualdad de género ${ }^{\circ}$ dentro de la organización, inclusive cuando el desarrollo y la implementación de la estrategia militar empezaron a tener prioridad sobre la propaganda. (lbid.).

Esto contradice el pensamiento de la historiadora peruana Cecilia Blondet, según la cual el PCP-SL "veía a las mujeres como inofensivas y ciudadanas de segunda clase" (BLONDET, 1996, p. 84). Por lo contrario, entre las motivaciones que podían conducir ciertas mujeres a integrarse a la organización, estaba "el problema del machismo y el maltrato a la mujer" (ASENCIOS, 2013) imperantes en la sociedad peruana y en sus propias familias. David, que entrevisté en 2012, me cuenta que su madre, campesina en la zona de Cangallo (Departamento de Ayacucho) durante la guerra, sufría de violencia doméstica a manos de su esposo, pero que al descubrir la gente del PCP-SL, decide ser parte de la organización, lo cual la empodera y le da fuerzas para enfrentar la doble opresión marital y estatal. Cabe señalar que el PCP-SL practicaba la mediación en caso de violencia familiar. Sin embargo, se debe diferenciar dos tipos de tratamiento moral en términos de justicia popular de género aplicada por el PCP-SL: 1) El tratamiento emancipador y constructivo, con el sistema informal de mediación (resolución alternativa de conflictos) en caso de violencia doméstica (psicológica y/o física) en la pareja, o de resolución no violenta de conflictos por asuntos internos a la familia o a la pareja (ligados a lo económico y social), sea entre miembros de la organización, o en la misma población civil que estaba en contacto con ellos; 2) El tratamiento represivo y a veces letal para erradicar la prostitución, el adulterio, la pornografía y la homosexualidad, así como el sexismo ordinario. De hecho, cuando el enemigo político del PCP-SL era una mujer, la primera herramienta que se desplegaba contra ella era el sexismo y la inferiorización por la biología, como se puede apreciar en El Diario, donde por ejemplo se menciona en

6 La expresión "igualdad de género " no es parte del vocabulario del Movimiento Femenino Popular quien solo manejaba los conceptos de «feminismo proletario " y « emancipación de la mujer». 
un título principal "La menopausia de Corazón Aquino" (1988), quien, nacida en 1933, fue presidente de las Filipinas de 1986 a 1992, y denunciada por el PCP-SL por su cercanía con USA y el tratado militar filipino-norteamericano. También era condenado el emparejamiento con el enemigo político en tiempo de guerra, como por ejemplo lo describe el antropólogo peruano Lurgio Gavilán, al contar que una mujer del PCP-SL enamorada de un policía, había sido ahorcada por los miembros de su propio partido (GAVILÁN, 2013, p. 79).

Finalmente, el matrimonio que se contraía entre miembros del PCP-SL era orientado a los objetivos políticos, es decir que había que "coadyuvar a la brega que ambos realizan por el comunismo". El PCP-SL no estaba en contra del aborto, y muchas mujeres combatientes pedían ellas mismas el aborto en tiempo de guerra ${ }^{7}$, lo cual era practicado por mujeres del PCP-SL, contrariamente a la idea según la cual había aborto forzado generalizado en el PCP-SL. Los.as hijos.as nacidos.as de mujeres en combate eran a menudo educado.as por "la masa". La maternidad era valorizada dentro del contexto de la "mujer-madre del pueblo" que era llamada a "unirse a la Guerra Popular" y a luchar por su "emancipación", rechazando la "esclavitud del hogar y del trabajo doméstico" y rechazando la "concepción burguesa" que ve la maternidad como función central en la vida de una mujer. La idea era que la "Guerra Popular" iba "forjando a la madre de nuevo tipo", para quien "sus hijos son todos los hijos del pueblo". En este sentido: "El proletariado celebra a la mujer que en su doble rol lucha con la clase oprimida por la transformación de la sociedad y entrega su vida y las de sus hijos por la revolución" (EL DIARIO, 1988, p. 14).

Las prisioneras políticas declaran en su testimonio escrito que "el desarrollo del MFP a nivel nacional constituyó una de las principales bases del trabajo de masas para el inicio de la lucha armada. El MFP aportó con el tercio activo del total de los combatientes del Ejército Guerrillero Popular (EGP), combatiendo de igual a igual con los varones, y su trabajo sirvió a incorporar el punto 14 del Programa de la Revolución Democrática que comienza con Por la igualdad de la mujer". Según Cruvinel (2014, b), "La inversión del Partido Comunista del Perú en el empoderamiento político de las mujeres en los años 1970, nos ayuda a entender porque, entre 1980 y 1992, la incorporación femenina en la Guerra Popular ha sido una de las más grandes en América Latina: $40 \%$ de las militantes eran mujeres que actuaron como protagonistas del proceso en posiciones de comando y decisión. Y 50\% de la dirección del Partido era compuesto por mujeres". Sin 
embargo, es menester precisar que no todas las mujeres que fueron parte del MFP participaron en la guerra. El EGP fue compuesto por alrededor de 3000 personas cuya responsabilidad era aplicar las estrategias militares maoístas, es decir: agitación y propaganda armada, paros armados, sabotaje, asaltos guerrilleros y aniquilamiento selectivo.

Según la investigación de Jaymie Patricia Heilman (2010b, pp. 178179) desde 1976, y más precisamente desde 1978, vario.as jóvenes maestras y maestros fueron tempranos militantes del PCP-SL en el Distrito de Carhuanca (Provincia de Vilcashuamán, Departamento de Ayacucho), en la medida en que habían sido testigos de abusos cometidos por los notables de la zona, y la ausencia de presencia policial propició la emergencia y desarrollo del PCP-SL en el distrito (HEILMAN, 2010b, p. 183). Empezaron entonces las "escuelas populares" con los alumnos, enseñándoles la obra de Mao y el uso de las armas ("revolver y dinamita"), así como convocando a reuniones, formando nuevas organizaciones de base, y desde agosto 1979, llamando a boicotear las elecciones presidenciales previstas para el 1 ro de mayo 1980 (lbid. p. 184). Además, desde 1976, la actividad política del PCP-SL había retomado en el Distrito de Luricocha, donde la hacienda de los padres de Augusta servía como "una de las primeras escuelas de formación militar del partido" (Ibid., p. 187).

El 10 de julio de 1980, Augusta, junto con una decena de hombres y mujeres, fue quien realizó la primera acción armada, en la modalidad de "asalto" y "robo" con "material explosivo" y "armas de fuego", contra la hacienda San Germán de Ayrabamba (NUEVA CRÓNICA, 2007, p. 3), cuyo propietario era César Parodi, sin que fuera detenida Augusta por las autoridades estatales, aunque éstas ya sabían en aquel momento que Augusta era "Nora", como consta en el expediente judicial del caso (CORTE SUPERIOR DE JUSTICIA, Cangallo 289/284. a). Por otra parte, la denunciante Flora Gutiérrez de Parodi cuenta que aparecieron varios campesinos con "palos, piedras, huaracas y ceniza con aji", pidiendo que se mate al hacendado, "porque es gamonal abusivo que los hace trabajar en forma abusiva...que la tierra era de ellos", y que el grupo principal de asaltantes, bajo la dirección de una mujer "de tez blanca" (probablemente Augusta) había repartido los bienes robados entre los campesinos de la hacienda, ofreciendo pagarles su semana de trabajo (lbid. b).

Augusta La Torre se oponía radicalmente a la matanza de campesinos o nativos por parte del PCP-SL, así como a la destrucción de la organización jerárquica de las comunidades campesinas. En este sentido, se opuso internamente a la dirección del PCP-SL por las matanzas de campesinos. En el caso de la hacienda de Ayrabamba, ella no ordena matar al hacendado a pesar de que los campesinos lo piden. El objetivo era armar a lo.as campe- 
sino.as, más no aniquilarlo.as. El Movimiento Femenino Popular logró juntar a miles de mujeres en todos los niveles de la organización maoísta, con el fin de preparar la "Guerra Popular" desde un marco de "violencia revolucionaria" que se quiso librar contra la "violencia organizada del Estado". En este contexto, fue por ende inseparable la lucha por la "emancipación" de las mujeres de la lucha de clases desde el "movimiento proletario". La mayoría fueron mujeres andinas, mestizas, indígenas, pero hubo también la participación de mujeres afroperuanas, un tema nunca investigado desde el feminismo afroperuano. Según los testimonios recogidos, las mujeres no realizaban el "tiro de gracia", contrariamente a lo que afirman trabajos anteriores (HENRÍQUEZ AYÍN, 2006, p. 19; KIRK, 1993, p. 14). Durante la guerra, el periódico El Diario, de circulación nacional, una vez en manos del PCP-SL, hizo muy presente, con innumerables artículos y por medio de la poesía, la lucha de las mujeres en las sociedades peruana, rusa y china.

Acerca de las luchas del movimiento de mujeres urbano-populares en Lima, el gobierno de Belaúnde crea en 1982 un "nuevo grupo de comedores" llamado "cocinas familiares", las cuales se sumaron a los ya existentes Comedores populares autogestionados (ollas comunes) desde 1978. En 1984, iniciado por Alfonso Barrantes, fundador de Izquierda Unida y entonces alcalde de Lima, aparece el Programa del Vaso de Leche, "un programa que funcionaba con comités operados por las madres de familia con apoyo estatal" (BEBBINGTON, SCURRAH, BIELICH, 2011, p. 312), destinado a madres gestantes y lactantes, menores de 0 a 5 años y 11 meses, y niños de 6 y 7 años. El mismo año, desde un discurso enfocado a los derechos, 25.000 madres de 33 distritos de Lima marcharon para pedir la oficialización del programa con una ley, la cual se promulgó en 1985 a nivel nacional, marcando un hito en la participación pública de las mujeres en la agenda política del país. Siendo elegido en 1985, el Partido Aprista Peruano (APRA) crea el Programa de Asistencia Directa (PAD), formando los Clubes de madres. Por no perder su autonomía, la mayoría de comedores autogestionados rechazaron la propuesta de afiliarse al PAD. Los alimentos se obtenían por donaciones de EE.UU., ONGs e iglesias principalmente (lbid. 294-295). En 1986, a raíz del Primer Encuentro Nacional de Comedores Autogestionarios, se crea la Comisión Nacional de Comedores Populares (CNC), que en 1988 hace su primera gran movilización en Lima, donde 10.000 mujeres protestan con el alza del precios y las medidas económicas, logrando progresivamente institucionalizar su movimiento, negociando con el Estado, el cual substituye el discurso de los derechos por la atención mínima a la sobreviviencia. A finales de los años 1980, el gobierno aprista hunde el país en una grave crisis económica, donde las bases de los comedores expresan su insatisfacción con las 
dirigentas quienes trabajan temas políticos con ONGs feministas, sin que fueran atendidas las necesidades básicas (Ibid. p. 297). El PCP-SL denuncia repetidas veces esta realidad en El Diario a lo largo de 1988, al mismo tiempo que intenta reforzar las divisiones existentes dentro del movimiento de mujeres para la alimentación, tratando de penetrar el movimiento, así como amenanzando a las dirigentas y a veces asesinándolas, lo cual significará una "crisis organizativa" para estas organizaciones femeninas (lbid., p. 300).

El 14 de noviembre de 1988, en pleno congreso partidario, Augusta La Torre muere en circunstancias no esclarecidas, sin que nadie del PCP-SL se haya enterado en ese entonces, salvo el comité central y algunos testigos cercanos a éste. Se ha especulado ampliamente sobre las posibles razones de su muerte. Lo cierto es que Augusta no era proclive al suicidio, ni estaba enferma. Habría más bien sido silenciada al ser vista como enemiga política de la dirección de su partido. Los y las militantes se enteraron de su muerte por la prensa a inicios de los 1990. Nunca se les informó de la causa verdadera. Se preguntan hasta hoy porqué y donde se oculta su cadáver, del cual se sabe que transitó embalsamado por una casa de Comas (suburbio de Lima) antes de ser trasladado a otra parte. Una vez informados, los prisioneros compusieron desde la cárcel de Canto Grande, el "Himno a la Camarada Norah", considerada por ellos como "La más grande heroína del Partido y la revolución":

Elevándose en la gloria / imperecedera de la historia / en inagotable sendero / de heroicidad comunista / El Partido y la Guerra Popular / heroína nos dio / por siempre recordada Camarada Nora / heroína nos dio / por siempre recordada Camarada Nora / Flameante bandera roja / firme desafiante contra el viento / luminoso ejemplo en dar la vida / por el Partido y la revolución / Acero rojo temple de Gonzalo / firme comunista gran dirigente / camarada Norah / firme comunista gran dirigente / camarada Norah / Torrente hermoso es tu sangre / que ha regado nuestra revolución / firme juramento de la clase / compromiso de rojos combatientes / en conquistar el poder hasta el Comunismo / en conquistar el poder hasta el Comunismo / Irradiando luz poderosa / marxismo-leninismo-maoísmo / y su aplicación creadora / pensamiento gonzalo en nuestra patria / luchando a muerte contra el vil revisionismo / con odio de clase barremos tres montañas / asaltamos los cielos / con odio de clase barremos tres montañas / asaltamos los cielos / Torrente hermoso es tu sangre / que ha regado nuestra revolución / firme juramento de la clase / compromiso de rojos combatientes / 
en conquistar el poder hasta el Comunismo / en conquistar el poder hasta el Comunismo / en conquistar el poder hasta el Comunismo.

A finales de los años 1980, se opera un autoritarismo desenfrenado del PCP-SL (también llamada "militarejo" por los ex miembros de la organización que critican esta fase de la guerra), cuando Oscar Ramírez Durand ("Camarada Feliciano") llega a remplazar a Augusta en la dirigencia del partido. Feliciano actúa en sentido contrario del pensamiento de Augusta, matando campesinos y nativos, hasta el punto de abusar sexualmente de jóvenes mujeres ${ }^{8}$ del PCP-SL (algunas de ellas reclutadas a la fuerza) ${ }^{9}$ (CVR (b), 2003, p.70), lo cual era común entre la gente que, según el PCP-SL "antirevisionista", "no aplicó la moral de clase" y "desprestigió la organización". De la misma manera, según el testimonio a la CVR del ex integrante del PCP-SL Abdel Cacha Collas, el dirigente Felipe Tenorio, quien era dirigente del Comité Zonal del Norte Medio" (CZNM) (norte de Lima) y "miembro suplente del Comité Central", "amaba el poder y las mujeres", tenía "relaciones paralelas" a su compromiso oficial con la "Camarada Carla", y cuando ella amenaza con denunciarlo, él le baja su posición política, además de haber "embarazado" a Elena lparraguirre (miembro del Comité Permanente y segunda esposa de Guzmán después de la muerte de Augusta La Torre) y de "hacerle perder el bebe" (CACHA COLLAS, 2001).

Algunos miembros del PCP-SL atribuyen el fracaso militar y político de la guerra en 1992, año de la captura de A. Guzmán, a la muerte de Augusta, y por ende a la muerte de la "línea (política) correcta". Según testimonios, "la línea cambia desde su muerte", y el fracaso ocurre "por problemas internos" y por "desvío (burgués) del camino", principalmente porque ella quería llevar a cabo la guerra desde el campo, mientras que la dirección del PCP-SL se encontraba en Lima (VIEJO TOPO, 2015). El 26 de mayo del 1988, es decir nueve meses antes de la muerte de Augusta, El Diario publica "El Pronunciamiento del Movimiento Femenino Popular", enarbolando el retrato de Mariátegui:

8 Sobre los abusos cometidos por mandos del PCP-SL a final de los años 80 e inicio de los 90 , ver los testimonios de la CVR : $n^{\circ} 100213 ; n^{\circ} 720009 ; n^{\circ} 102170 ; n^{\circ} 437591$.

9 Entrevista con el Dr. Carlos Rivera, abogado en Derechos Humanos en el Instituto de Defensa Legal (IDL), Lima, 2011. 


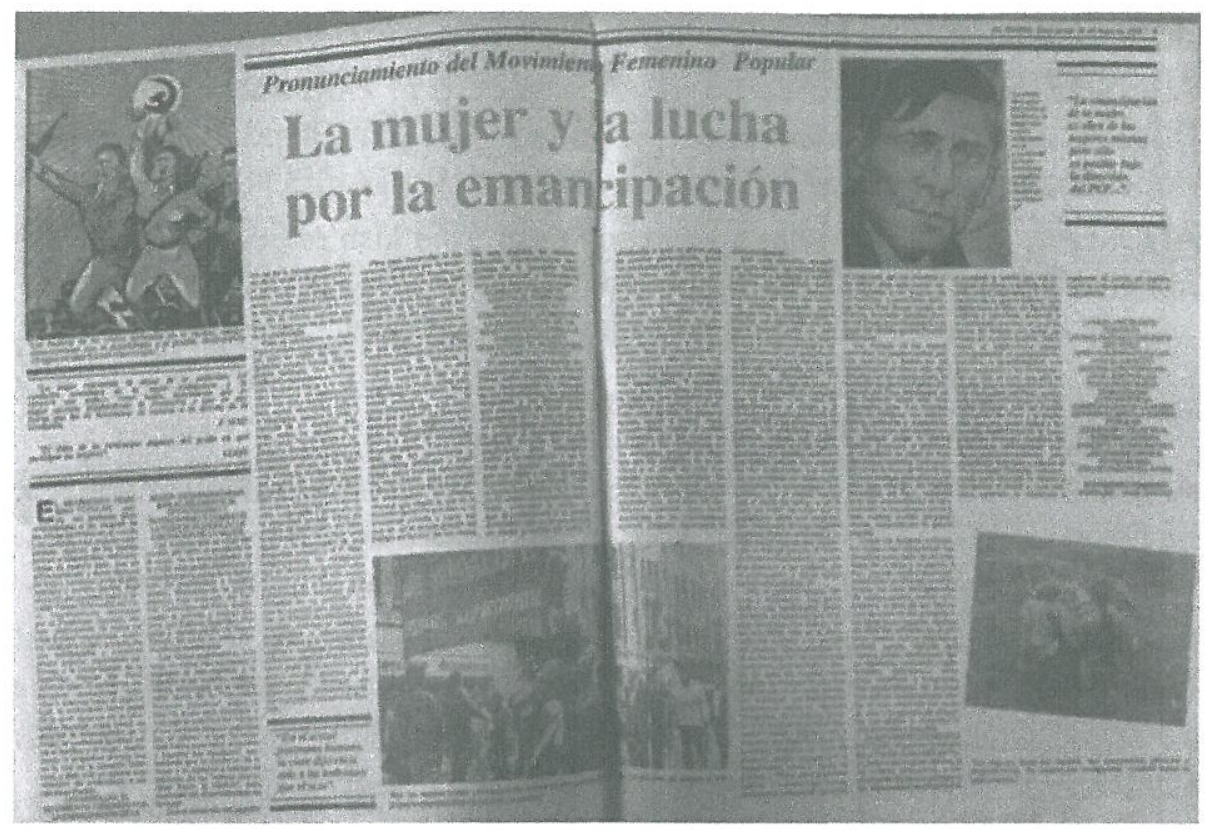

Pronunciamiento del Movimiento Femenino Popular, El Diario, 26 de mayo de 1988, Lima.

Como lo afirma Heilman, se ha "restado importancia al significado político de Augusta La Torre, evaluándola solamente en relación con su esposo, sin lograr tratarla como militante por si sola. La familia -bajo la forma de su esposo- ha efectivamente hecho sombra al legado político de Augusta La Torre" (HEILMAN, 2010a, p. 166). Hoy día, la memoria de Augusta está siendo disputada entre, por un lado, los miembros del MOVADEF -Movimiento por la Amnistía General y los Derechos Fundamentales y el Movimiento Hijas del Pueblo, herederos del PCP-SL con miras a participar en la vida política del país- que infantilizan a Augusta al llamarla «Augustita» y «seguidora» del camino de Guzmán (CÍRCULO FEMENINO «MARÍA PARADO DE BELLIDO», 2015), construyéndola, según uno de mis entrevistados, como «ícono inofensivo». Por otro lado, los disidentes del PCP-SL ven en ella la que guió la «Revolución proletaria» del Perú. Pareciera que el legado de esta "revolución" está resurgiendo entre los disidentes que no están de acuerdo en seguir la vía electoral (como lo hace sin éxito desde 2009 el MOVADEF), y que ven en Mariátegui y La Torre, la manera "correcta» de «trabajar con las masas» y de lograr nuevas formas de ciudadanía. Para mucho.as, Augusta La Torre, por «encabezar la línea proletaria» y oponerse a la masacre de campesino.as, fue, hasta 1988, la «verdadera heroína y lideresa de la revolución y de la Guerra Popular». 


\section{Biblografía}

ALLENDE, S. (1967): Crítica a la Alianza para el Progreso. Montevideo, Discurso en la Universidad de la República, Uruguay. http://www.memoriapoliticademexico.org/Textos/6Revolucion/1967-ALPRO-SA.html ANDREAS, C. (1986): When Women Rebel: The Rise of Popular Feminism in Peru. Westport, Connecticut: Lawrence Hill \& Company.

ANDREAS, C. (1990/1991): "Women at war », Peru's Shining Path ». NACLA Report on the Americas, Vol. XXIV, no 4, December/January, pp. 20-27.

ANDREAS, C. (2004): " 'It's Right to Fight'. Women Insurgents in Peru ». En DOMBROWSKI, N.A. (ed.), Women and War in the Twentieth Century: enlisted with or without consent. Routledge: New York, pp. 312-328.

ASENCIOS LINDO, R. D. (2013): Múltiples rostros, un solo sendero : aproximaciones a las motivaciones y militancia de jovenes encarcelados de Sendero Luminoso en Lima, 1989-1992, Tesis de Magíster en Sociología, Lima, PUCP.

BARRIG, M. (1993): « Liderazgo femenino y violencia en el Perú de los 90 ». Debates en Sociología, no18, pp. 89-112.

BEBBINGTON A., M. SCURRAH, C. BIELICH (2011): "El movimiento de mujeres urbano-populares y las organizaciones de mujeres para la alimentación ». En Los movimientos sociales y la política de la pobreza en el Perú, Lima: IEP, CEPES, Grupo Propuesta Ciudadana, pp. 285-344.

BLONDET, C. (1996): «In No-Man's Land: Poor Women's Organizations and Political Violence in Lima's Neighborhoods ». En FRIEDMAN J., R. ALBERS, L. AUTLER (eds.), Emergences: Women's Struggles for Livelihood in Latin America, UCLA, Latin American Studies, Vol. 82, pp. 79-90.

BURT, J.-M. (2010): " Los usos y abusos de la memoria de María Elena Moyano ». A Contra corriente, vol. 7, no 2, pp. 165-209.

CACHA COLLAS, A. K. (2001): Testimonio de Abdel Kudy Cacha Collas a la Comisión de la Verdad y Reconciliación (CVR), n 100054.

CANYELLES, C. (2012): «Ser mujer y revolucionaria » (no publicado).

CASAFRANCA, J. (1996): Las mujeres productoras de alimentos en Perú. Diagnóstico y políticas. Programa de Análisis de la Políica del Sector Agropecuario frente a la Mujer Productora de Alimentos en la Región Andina, el Cono Sur y el Caribe, Instituto Interamericano de Cooperación para la Agricultura (IICA), Banco Interamericano de Desarrollo, San José, C.R.: IICA. CÍRCULO FEMENINO "MARÍA PARADO DE BELLIDO » (2015): Norah Presente. $70^{\circ}$ Aniversario 1945-2015. (Editorial desconocida), Lima. 
COMISIÓN PERMANENTE DE HISTORIA DEL EJÉRCITO DEL PERÚ (CPHE) (2012): En honor a la verdad. Cuartel General del Ejército, Lima.

COMISIÓN DE LA VERDAD Y RECONCILIACIÓN (CVR) (a) (2003): "El impacto diferenciado de la violencia", Tomo VIII, Capítulo 2, Informe final de la CVR. Lima: CVR. 9 vols.

COMISIÓN DE LA VERDAD Y RECONCILIACIÓN (CVR) (b) (2003): « Los actores armados », Tomo II, Capítulo 1, Informe final de la CVR. Lima: CVR. 9 vols.

CORTE SUPERIOR DE JUSTICIA, Cangallo 289/284. a. Instrucción $n^{\circ}$ 284/80. Informe contra Herbert Rolando Llamocca y otros, por delito de asalto y robo y otros, en agravio de César Parodi Vasallo y otros.

CORTE SUPERIOR DE JUSTICIA, Cangallo 289/284. b. Manifestación de Doña Flora Gutiérrez de Parodi, Ayacucho, 02-05-1981.

CRUVINEL, M. (a) (2014): "(Des)locando (I)ma(r)gens: Breve iconografía da trincheira". Linha Mestra, n² 24, Jan-Jul. pp. 133-142.

CRUVINEL, M. (2015): "Mujer y Testimonio. De las (im)posibilidades de recordar, olvidar y decir". MOARA, Revista Electrónica del Programa de Posgrado en Letras, Universidad Federal do Pará, Brasil, no 44, pp. 22-41.

CRUVINEL, M. (b) (2014): Video The skin I exist/(re)exist in, presentado en 8th International Gender and Language Association (IGALA) Conference, Junio 5-7, Shifting Visions: Gender, Sexuality, Discourse and Language, Simon Fraser University, Harbour Centre, Vancouver, Canada. https://mulheresemdiscurso.wordpress.com/membros/monica-cruvinel/

CULTURALES 1 ro de MAYO (2011): "Honor y Gloria a la Camarada Norah ». n 8, Sept.-Oct., p. 5.

DEGREGORI, C. I. (2007): "¿Por qué apareció Sendero Luminoso en Ayacucho? El desarrollo de la educación y la generación del 69 en Ayacucho y Huanta". En PÉROTIN-DUMON A. (ed.), Historizar el pasado vivo en América Latina http://etica.uahurtado.cl/historizarelpasadovivo/es_contenido.php

El DIARIO (1988): "La Guerra Popular y la Madre de Nuevo Tipo". Lima, mayo, p. 14.

FEDERICI, S. (2010): Calibán y la Bruja. Mujeres, cuerpo y acumulación originaria. Traficantes de sueños, Madrid.

FELICES-LUNA, M. (1999): Les femmes "terroristes »: le cas du Sentier Lumineux du Pérou. Université de Montréal, Montréal.

FELICES-LUNA, M. (2007): « L'implication des femmes au sein des groupes armés contestataires : la déviance au service d'une entreprise citoyenne ». Champ pénal / Penal Field, vol. IV. 
FERNÁNDEZ MONTENEGRO, B. (2010): «La reforma agraria de 1969 : 40 años después las mujeres tienen algo que contar ». Chacarera, $n^{\circ} 40$, pp. 14-16.

GAVILÁN SÁNCHEZ, Lurgio (2013): Memorias de un soldado desconocido. Autobiografía y antropología de la violencia. Lima, Instituto de Estudios Peruanos (IEP), México, Universidad Iberoamericana (Serie Estudios sobre Memoria y Violencia, 3).

GUINÉ, A. (2014): «Crónica del primer coloquio peruano sobre el conflicto armado interno ». Mediapart, 13 de agosto. https://blogs.mediapart. $\mathrm{fr} /$ edition/mediapart-en-espanol/article/130814/cronica-del-primer-coloquio-peruano-sobre-el-conflicto-armado-interno

GUZMÁN, A. \& E. IPARRAGUIRRE (2014): Memorias desde Némesis. http://bvk.bnp.gob.pe/admin/files/libros/801_digitalizacion.pdf HEILMAN, J. P. (a) (2010): « Family Ties: The Political Genealogy of Shining Path's Comrade Norah". Bulletin of Latin American Research, vol. 29 no. 2, abril-junio, pp. 155-169.

HEILMAN, J. P. (b) (2010): Before the Shining Path. Politics in Rural Ayacucho, 1895-1980. Stanford: Stanford University Press.

HENRÍQUEZ AYÍN, N. (2006): Cuestiones de género y poder en el conflicto armado en el Perú. Lima: CONCYTEC.

KAMPWIRTH, K. (2003): Women and Guerrilla Movements, Nicaragua, El Salvador, Chiapas, Cuba. The Penn State University Press.

KIRK, R. (1993): Grabado en piedra. Las mujeres de Sendero Luminoso. Lima: Instituto de Estudios Peruanos (IEP).

KYMLICKA, W. (1996): Ciudadanía multicultural. Una teoría liberal de los derechos de las minorías. Barcelona: Paidós.

LÓPEZ, F. (2012): Feminismos desde las fronteras: Repensando la emancipación femenina y la revolución en el Partido Comunista del Perú-Sendero Luminoso. Tesis de Magíster en Estudios Culturales, Lima, PUCP.

MARIÁTEGUI, J. C. (1924): "Las reivindicaciones feministas". Mundial, 19 de diciembre, Lima.

MONGE, C. (1989): «La Reforma Agraria y el Movimiento Campesino ». Debate Agrario, $n^{\circ} 7$, Centro Peruano de Estudios Sociales (CEPES), Lima, pp. 63-84.

MOVIMIENTO FEMENINO POPULAR (MFP) (1974): El marxismo, Mariátegui y el movimiento femenino. Lima. https://www.marxists.org/espanol/ adrianzen/mmmf/index.htm. 
MOVIMIENTO FEMENINO POPULAR (MFP) (1973): Declaración de Principios y Programa del Movimiento Femenino Popular (proyectos), Rimariyña Warmi. Ayacucho, $\mathrm{n}^{\circ}$ 2, Sept.

NUEVA CRÓNICA (2007): Camino a Ayrabamba. Lima, Canto Grande: Ediciones Nueva Crónica.

PARTIDO COMUNISTA DEL PERÚ (1988): Base de discusión de la política general, « Línea de masas ».

http://www.pagina-libre.org/MPP-A/Textos/PCP1988/LinMasas.html ROJAS ALLENDE, G. (2003): Modernización y organización de mujeres : el tránsito a la esfera pública en la ciudad de Ayacucho (1960-1980). Informe de práctica pre profesional de historia, Escuela de formación profesional de arqueología e historia, Facultad de Ciencias Sociales, Universidad Nacional de San Cristóbal de Huamanga, Ayacucho, Junio.

ROMERO-DELGADO, M. (2016) : " Las «Otras Olvidadas ». Apuntes sobre agencia y transgresión con nombre de mujer(es) ». Por publicarse en el $n^{\circ} 7$ de EOLLE (Est Ouest Langues Littératures Échanges), Groupe de Recherches Identités et Cultures (GRIC), Université du Havre.

SÉMELIN, J. (2005): "Massacres et génocides : L'apport des sciences sociales à leur étude ». La Violence et ses causes: où en sommes-nous? Paris: UNESCO.

SCOTT PALMER, D. (2014): "The Influence of Maoism in Peru ». En COOK A. C. (ed.), Mao's Little Red Book. A Global History. Cambridge University Press, pp. 130-146.

TRAT, J. (1997): «Engels et l'émancipation des femmes ». Europe Solidaire Sans Frontières.

VARGAS, V. (2008): Feminismos en América Latina; Su aporte a la política y a la democracia. Lima: Programa Democracia y Transformación Global, UNMSM, Centro Flora Tristán.

VELASCO ALVARADO, J. (1969): Mensaje a la Nación con motivo de la promulgación de la Ley de la Reforma Agraria. Lima, 24 de Junio. https:// www.marxists.org/espanol/tematica/agro/peru/velasco 1969.htm VELASCO ALVARADO, J. et. al. (1971): Texto único de la ley de reforma agraria. Decreto Ley No. 17716. Oficina Nacional de Información, Empresa editora del Diario Oficial "El Peruano", Lima, 13 de Julio.

VIEJO TOPO (2015): En defensa de Mariátegui y Norah. Lucha contra el revisionismo. Lima: Viejo Topo, marzo. https://fr.scribd.com/ doc/275536829/En-defensa-de-Mariategui-y-Norah-Lucha-contra-el-revisionismo. 
VILLASANTE CERVELLO, M. (2012): Violencia de masas del Partido Comunista del Perú-Sendero Luminoso y campos de trabajo forzado entre los Asháninka de la Selva Central. Datos preliminares de una investigación de antropología política sobre la guerra interna en el Perú. Revista sobre Cultura, Democracia y Derechos Humanos, $n^{\circ} 9$, Diciembre, IDEHPUCP, Lima. 